\title{
Zeytin Çekirdeği Tozu İlave Edilmiş Polipropilen Kompozitinin Aşınma ve Fiziksel Özellikleri
}

\author{
Münir TAŞDEMİR ${ }^{1 *}$, Alim KAŞTAN² \\ ${ }^{1}$ Marmara Üniversitesi, Teknoloji Fakültesi, Metalurji ve Malzeme Mühendisliği. Bölümü, İstanbul, Türkiye \\ ${ }^{2}$ Organize Sanayi Bölgesi Mesleki ve Teknik Anadolu Lisesi, Antalya, 07190, Türkiye \\ (ORCID: 0000-0001-8635-7251) (ORCID: 0000-0002-6514-3796)
}

\begin{abstract}
$\ddot{O} z$
Bu çalışmada; toz haline getirilmiş zeytin çekirdeği tozları polipropilen (PP) polimeri içerisine \%5-10-15 ve 20 oranında katılarak çift vidalı ekstrüzyon makinesinde karıștırılarak dört farklı kompozit malzeme üretilmiştir. Polipropilen ve zeytin çekirdeği tozları arasındaki uyumluluğu artırmak için kompozite \%5 oranında maleik anhidrit aşılanmış polipropilen (MA-g-PP) eklenmiştir. Daha sonra granül halindeki kompozit malzemeler enjeksiyon kalıplama yöntemi ile kalıplanarak standart test numuneleri basılmıştır. Kompozitin çeşitli fiziksel ve aşınma özellikleri hakkında bilgi edinmek için Vicat yumuşama sıcaklığı, 1sıl çarpılma sıcaklığı, nem emme oranı, erime akış indeksi, oksijen indeksi ve aşınma testleri yapılmışır. Ayrıca zeytin çekirdeği tozlarının matris içerisinde dağılımlarını görmek için darbe testleri sonucundan elde edilen kırık yüzeylerden taramalı elektron mikroskobisi (SEM) ile fotoğrafları çekilmiştir. Yapılan testlerin sonuçlarına göre, matris içerisinde zeytin çekirdeği toz (ZÇT) oranının artmasıyla; Vicat yumuşama sıcaklığı, 1sıl çarpılma sıcaklığı, nem emme mikrarı ve aşınma oranı değerlerinin yükseldiği buna karşılık erime akış indeksi ve oksijen indeksi değerlerinin ise düştüğü tespit edilmiştir.
\end{abstract}

Anahtar Kelimeler: Polipropilen, biyo kompozit, zeytin çekirdeği tozu, fiziksel özellikler, aşınma oranı, maleik anhidrit.

\section{Wear and Mechanical Properties of Olive Pit Powder Added Polypropylene Composite}

\begin{abstract}
In this study, powdered olive pits were added to polypropylene at a rate of 5-10-15 and 20\%, and four different polymer composite materials with olive pits were produced by twin screw extruder. 5\% maleic anhydride grafted polypropylene (MA-g-PP) was added to the composite to increase the compatibility of polypropylene and olive pits. Later, the granular composite material was molded by injection molding method and standard test samples were molded. In order to learn about the physical and wear properties of the composite, Vicat softening point, heat deflection temperature, moisture content, melt flow index, limit oxygen index and wear tests were performed. In addition, in order to see the distribution of olive pit powders in the matrix, photographs of the broken surface were taken with scanning electron microscopy. According to the results of the tests, with the increase of olive pits powder ratios in the matrix; It was determined that the Vicat softening point, heat deflection temperature, moisture content and wear rate values increased while the melt flow index and limit oxygen index values decreased.
\end{abstract}

Keywords: Polypropylene, bio composites, olive pit powder, physical properties, wear rate, maleic anhydride.

\section{Giriș}

Akdeniz bölgesinde dünya zeytinyağı üretiminin yaklaşık \%95'ini İspanya, Yunanistan, İtalya, Tunus ve Türkiye yapmaktadır [1]. Zeytinyağı çıkarma işleminden sonra, zeytin meyvesinin ağırlı̆̆ının \%3035 civarında katı lignoselülozik atık ortaya çıkar. Bu atıkların kimyasal bileşimi; esas olarak lignin, hemiselüloz ve selülozdan oluşmaktadır. Zeytin atığı diğer birçok kullanımının yanı sıra dolgu malzemesi olarak kullanımı da büyüyen bir potansiyele sahiptir. Lignoselülozik bazlı bu malzemeler ucuz, sert ve düşük yoğunluklu malzemelerdir. Polipropilenin aksine zeytin çekirdeği gibi lignoselülozik malzemelerin üzerindeki polar grupların olması nedeniyle bu malzemeler nemi kolayca emer. Yani

*Sorumlu yazar: munir@marmara.edu.tr

Gelis Tarihi: 07.02.2021, Kabul Tarihi: 09.04.2021 
polipropilen apolarken zeytin çekirdeği polardır. Bu yüzden uyumsuzdurlar ve uyumlu hale getirilmeleri gerekmektedir. $\mathrm{Bu}$ durumda sisteme yüzey modifikasyonunu artıran uyumluluk maddeleri eklenmektedir. Böylelikle matris ve dolgu yüzeyi arasında bir yapışma sağlanır [2-6]. Literatürde zeytin çekirdeği tozları ile yapılmış çalışmalar mevcuttur fakat aşınma davranışları üzerine pek çalışma yoktur. Kılıçaslan [7]yapmış olduğu bir çalışmada zeytin sıkma işleminden sonra arta kalan zeytin pirinasının polyester matrisli kompozitlerde kullanımını araştırmıştır. Çalışmasında polyester içerisine \%30-60 arasında zeytin pirinası eklemiştir. Saf polyester ve elde ettiği kompozit malzemelerin mekanik değerlerini karşılaştırmıştır. Çalışmasının sonucunda polyester içindeki zeytin çekirdeği oranının artması ile elastiklik modülü ve akma gerilmesinin azaldığını rapor etmiştir. Taşdemir [8] ise bir çalışmasında polipropilen içerisine zeytin çekirdeği ve badem kabuğu tozlarını katarak elde ettiği polimer kompozitinin özelliklerini incelemiştir. Elde ettiği polimer kompozitinde zeytin çekirdeği ve badem kabuğu tozlarının oranının artmasıyla su emme miktarının, ısıl çarpılma sıcaklığının ve Vicat yumuşama sıcaklığının arttığını çalışmasında rapor etmiştir. Bunlara ek olarak sürtünme katsayısının ve aşınma oranının da artan zeytin çekirdeği ve badem kabukları ile arttığını tespit etmiştir. Koutsomitopoulou ve arkadaşlarının [9] yapmış oldukları bir çalışmada polilaktik asit içerisine zeytin çekirdeği tozları katarak bir polimer kompoziti üretmişlerdir. Elde ettikleri polimer kompozitinin biyolojik olarak bozulabilir bir ürün olduğunu belirlemişlerdir. Aynı zamanda zeytin çekirdeğinin oranının artmasıyla polimer kompozitinde fiziksel ve mekanik değerlerin nasıl değiştiğini de belirlemişlerdir. Djidjelli ve arkadaşları ise [10], polivinil klorür içerisine \%5-15-25 oranlarında zeytin çekirdeği katarak elde ettikleri polimer kompozitlerinin mekanik özelliklerini incelemişlerdir. Zeytin çekirdeklerinin yaklaşı $100 \mu \mathrm{m}$ olacak şekilde ögütüp bir kısmına kimyasal işlem uygulamadan bir kısmına ise benzil klorür kullanarak kimyasal işleme tabi tutmuşlardır. Çekme testleri sonucunda kimyasal işlem gören ve görmeyen zeytin çekirdeği katkılı kompozitlerin oranının artmasıyla saf polivinil klorüre oranla daha düşük uzama ve çekme mukavemeti değeri verdiklerini belirlemişlerdir. Aynı zamanda benzil klorür ile yapılan kimyasal işlemin mekanik değerlerde çok fazla etkisinin olmadığını da belirlemişlerdir. Gümüş ve arkadaşlarının [11] yapmış oldukları bir çalışmada ise zeytin çekirdeği dolgulu polipropilenin dinamik mekanik özelliklerini incelemişler ve artan zeytin çekirdeği oranı ile bazı mekanik ve 1sısal özelliklerin iyileştiğini çalışmalarında rapor etmiş̧lerdir. Aynı zamanda atık zeytin çekirdeği tozlarının odun plastik kompozitlerinde (wood polymer composites- WPC) bir dolgu maddesi olarak kullanımının olduğunu ortaya koymuşlardır. Ayrılmış ve arkadaşlarının [12] yapmış oldukları bir çalışmada, polipropilen içerisine selüloz bazlı ürün olan odun talaşı ve zeytin küspelerini katarak bir polimer kompoziti elde etmişlerdir. Matris ve dolgu maddeleri arasındaki uyumluluğu arttırmak için ise matrise maleik anhidrit ile aşılanmış polipropilen (MA-g-PP) ilave etmişlerdir. Elde ettikleri polimer kompozitinin su direncinde ve eğilme özelliklerinde önemli bir değişimin olmadığını ve uyumluluk maddesinin eğilme dayanımında bir etkisinin olmadığını çalışmalarında rapor etmişlerdir. Öztürk ve arkadaşları ise [13] pirina atığı katkılı termoplastik kompozitlerin termo-kinetik mikser ile üretimi başlıklı çalışmasında yüksek yoğunluklu polietilen içerisine \%0-10-20-30-40 ve 50 oranlarında pirina ilave edip bir polimer kompoziti üretmişlerdir. Elde ettikleri polimer kompoziti içerisindeki pirina oranının artmasıyla çekme mukavemeti ve eğilme modülü değerlerinin düştüğü buna karşılık elastiklik modül değerinin ise arttığını tespit etmişlerdir.

Bu çalışmada, ülkemizde bol miktarda üretilmekte olan zeytin çekirdeklerinin değerlendirilmesi hedeflenmiş̧ir. Bunların öğütülerek toz haline getirilmesi ve polipropilen içerisine bir çeşit dolgu malzemesi olarak katılması sağlanmıştır. Polipropilen ve zeytin çekirdeği arasındaki yapışmanın sağlanması için sisteme maleik anhidrit aşılı polipropilen (MA-g-PP) \%5 oranında ilave edilerek bazı fiziksel ve aşınma özellikleri belirlemiş ve sonuçlar rapor edilmiştir.

\section{Materyal ve Metot}

\subsection{Kompozisyon ve malzemeler}

Zeytin çekirdeği tozunun kompozit içerisinde oluşturacağı oranları değiştirerek 5 farklı grup hazırlanmıştır. Aşağıda Tablo 1'de oranlar verilmiştir. Kullanılan polipropilen Moblen EP 3307 kodlu Lyondell Basell tarafından üretilen bir polimerdir. Yoğunluğu $0,900 \mathrm{~g} / \mathrm{cm}^{3}$, erime akış indisi $15 \mathrm{~g} / 10$ dak. $\left(230{ }^{\circ} \mathrm{C}-2,16 \mathrm{~kg}\right)$, 1 sıl çarpılma sıcaklığ $195{ }^{\circ} \mathrm{C}$ 'dir. Zeytin çekirdekleri Gemlik'te yaşayan yerel halktan temin edilmiştir. 
Tablo 1. PP/ZÇT/MA-g-PP polimer kompozitinin karışım oranları

\begin{tabular}{cccc}
\hline Gruplar & PP $(\%)$ & ZÇT $(\%)$ & MA-g-PP $(\%)$ \\
1 & 100 & - & - \\
2 & 90 & 5 & 5 \\
3 & 85 & 10 & 5 \\
4 & 80 & 15 & 5 \\
5 & 75 & 20 & 5 \\
\hline
\end{tabular}

\subsection{Numune hazırlama}

Zeytin çekirdeklerinden toz şeklinde partiküller üretmek için Siemens marka öğütücüde kuru olarak ögütülmüş ve kompozitte yaklaşık 40 mikron boyutundaki tozlar kullanılmıştır. Şekil 1' de bu yöntemin fotoğrafları ve zeytin çekirdeğinin yapısı verilmiştir. Zeytin çekirdeği tozları ve polipropilen Yamato ADP-31 tipi firında matris ile karıştırılmadan önce $105^{\circ} \mathrm{C}^{\prime}$ de 24 saat boyunca kurutulmuştur. Aşağıdaki şekilde bu deneysel çalışmanın aşamaları verilmiştir.

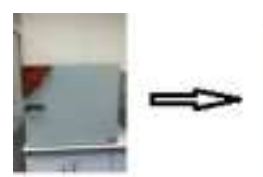

a) Kurutma

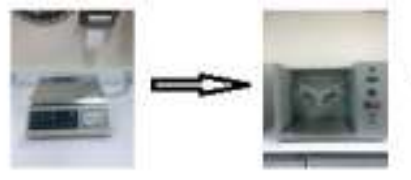

c) Karıştırma

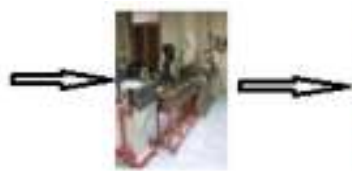

d) Ekstrüzyon

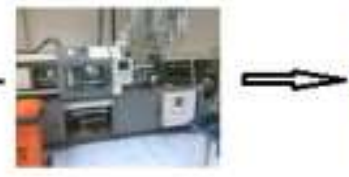

e) Enjeksiyon

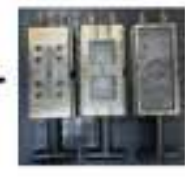

f)Numuneler

Şekil 1. PP/ZÇT/MA-g-PP polimer kompozitinin deneysel çalışma aşamaları

Daha sonra zeytin çekirdeği tozları ve polipropilen granülleri Patterson marka karıştırıcıda yirmi dakika boyunca karıştırılmıştır. Bir sonraki aşamada ise Mikrosan marka çift vidalı ekstrüderde 15-20 bar basınç altında, 30 dev/dak vida dönüş hızında ve $190-220{ }^{\circ} \mathrm{C}$ arasındaki sıcaklıklarda eritilerek karışımları gerçekleştirilmiştir. Bu işlemden sonra tekrar firında $105^{\circ} \mathrm{C}^{\prime}$ de 24 saat boyunca kurutuldu ve test numuneleri enjeksiyon sicaklığ $190-220^{\circ} \mathrm{C}$, enjeksiyon basınç1 $90-110$ bar ve vida dönme hızı $20 \mathrm{dev} /$ dak olan bir enjeksiyon makinesinde test numuneleri basılmıştır.

Tablo 2. PP/ZÇT/MA-g-PP polimer kompozitinin kalıplama şartları

\begin{tabular}{lrr}
\hline İşlem & Ekstrüzyon & Enjeksiyon \\
\hline Sicaklık $\left({ }^{\circ} \mathrm{C}\right)$ & $190-220$ & $190-220$ \\
Basınç (bar) & $15-20$ & $90-110$ \\
Kalıpta bekleme süresi (sn) & - & 20 \\
Vida hızı (dev/dak) & 30 & 20 \\
Kalıp sıcaklığı $\left({ }^{\circ} \mathrm{C}\right)$ & - & 40 \\
\hline
\end{tabular}
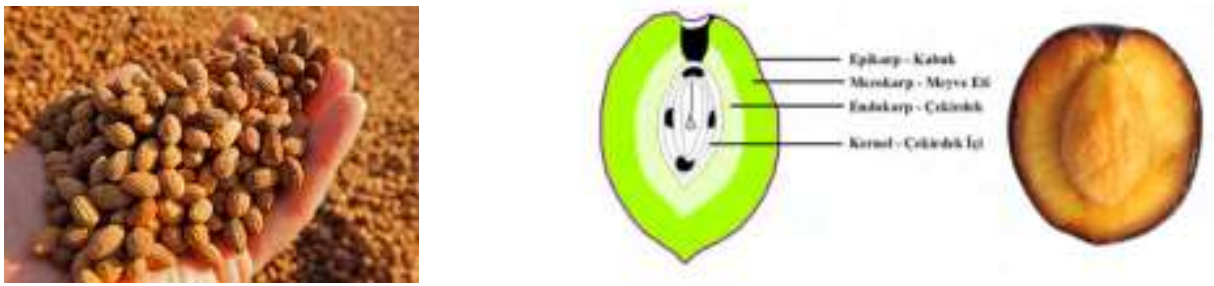

https://bioplasticsnews.com/2020/05/08/bioplastic-packaging-olive-wastel https://docplayer.biz.tr/47553964-Zeytin-ve-zeytinyagi.html

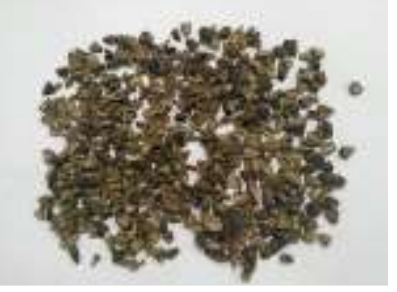

Zeytin çekirdeği

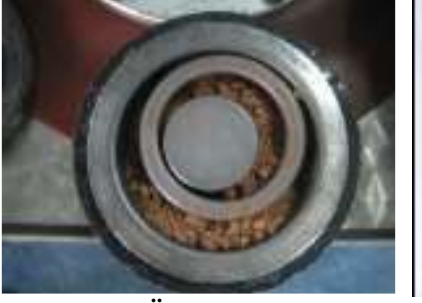

Öğ̈̈tücü

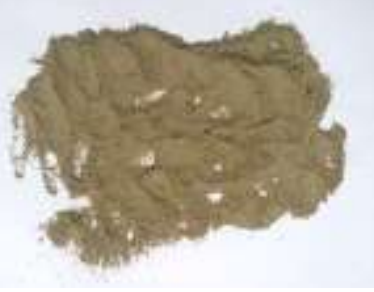

Toz hali

Şekil 2. Zeytin çekirdeğinin yapısı ve toz haline getirilmesi 


\subsection{Karakterizasyon}

Elde edilen gruplardan testler için beş adet numune alınmıştır ve ortalamaları verilmiştir. Isıl çarpılma sıcaklığı (HDT) testi ISO 75'e göre ve Vicat yumuşama sıcaklığı ise ISO 307'e göre Ceast marka test cihazı ile yapılmıştır. Isıl çarpılma sıcaklığı testi Metod A' ya göre yapılmıştır. Eğilme mukavemeti sabiti 1,8 MPa ve numuneye silikon yağının ssıtma hızı ise saatte $120^{\circ} \mathrm{C}$ alınmıştır. Numune boyutları 80x10x4 mm olup mesnetler arası mesafe de 64 mm'dir. Numuneler yatay (flatwise) olarak test edilmiş olup $0,34 \mathrm{~mm}$ eğim miktarındaki sıcaklıklar kayıt edilmiştir. Numenelere uygulanan yük aşağıdaki formül ile belirlenmiştir.

$\mathrm{F}=2 \cdot \sigma \cdot b \cdot \mathrm{h}^{2} / 3 \mathrm{~L}$

Burada, $\sigma$ : Eğilme mukavemeti (MPa), b: Numune genişliği (mm), h: Numune kalınlığı (mm), L: Mesnetler arası mesafe (mm), F: Numuneye uygulanan kuvvet (N)' dur. Bu formüle göre değerler yerine konulduğunda numune üzerine 3 Newton yük uygulanmıştır.

Vicat testi metod A'ya göre yapılmıştır. Vicat testinde numuneye 10 Newton yük uygulanmış ve silikon yağının ısıtma hızı ise saatte $120{ }^{\circ} \mathrm{C}$ alınmıştır. Bu sıcaklıkta ve $10 \mathrm{~N}$ yük altında cihazdaki batıcı ucun numuneye $1 \mathrm{~mm}$ girdiği andaki sıcaklık rapor edilmiştir. Burada kullanılan numunelerin boyutu 20x20x4mm olarak alınmıştır.

Erime akış indeksi (MFI) testi ISO 1133 standardına göre Zwick 4100 marka cihaz ile yapılmıştır. Bu testte, malzeme sıcaklık ile eritilerek üzerine belirli bir yük uygulanır ve bu yük altında kılcal bir borudan 10 dakika içerisinde ne kadar malzemenin aktığ belirlenir. Burada numuneye $230{ }^{\circ} \mathrm{C}$ sıcaklık uygulanmış olup 2,16 kg yük altında akışa zorlanmıştır. Bu değerlerin seçilmesinin nedeni ise standartta polipropilen için kullanılan değerler olmasıdır. Belirli bir süre sonunda akan malzeme tartılmış ve aşağıdaki formülde değerler yerine konularak MFI değeri belirlenmiştir. Burada, m: Belirli sürede (T) akan toplam numune ağırlı̆̆ (gr) ve t: Belirli süre (sn)'dir.

$\mathrm{MFI}=\mathrm{m} .600 / \mathrm{t}$

Nem ölçüm tetleri ASTM D6980’ e göre Kern marka nem ölçüm cihazı ile yapılmıştır. Cihaz sıcaklığa dayanıklı numune kabının içerisine koyulan ürünü önce tartar ve hafızaya alır sonra halojen lambası ile $105^{\circ} \mathrm{C}$ 'ye kadar 1sıtma yaparak numuneyi kurutur. Cihaz ürünün kuruduğunu terazideki değerlerin değişiminden anlayarak ısıtmayı durdurur ve nemli miktar ile kuru miktarı bildiği için arasındaki farkı hassas bir şekilde \% nem olarak ekrana getirir. Burada kullanılan numune boyutlarının ölçüleri 10x10x4 mm'dir.

Limit oksijen indeksi testleri ISO 4589' e göre Devotrans marka LOI test cihazı ile yapılmıştır. Oksijen indeksi testi bir plastiğin ateş çekildikten sonra yanmaya devam etmesi için havada bulunması gereken minimum oksijen miktarını gösterir. Deney parçasının boyutları standartta belirtilen tip 1'e göre basılmış olup boyutlar $80 \times 10 \times 4 \mathrm{~mm}$ ' dir. Bu testte üst yüzey tutuşması olan A tipi tutuşma uygulanmıştır. LOI değeri bulunana kadar yaklaşık 10-15 adet numune test edilmiştir.

Aşınma testleri DIN 53516 standardına göre Devotrans DA5 marka tambur tipi aşınma test cihazında yapılmıştır. Bu test için numunelerin kalınlığı $7 \mathrm{~mm}$ ve çapları ise $15,5 \mathrm{~mm}$ alınmıştır. Tamburun dönüş hızı dakikada 40 devir olarak alınmıştır. Numunelere uygulanan yük $\left(\mathrm{F}_{\mathrm{N}}\right) 10 \mathrm{~N}$ ve aşındırma mesafeleri (L) ise 20-40-60 ve 80 metre olacak şekilde uygulanmıştır. Aşınma sonucunda meydana gelen ağırlık kaybının bulunması için deneyden önceki ve deneyden sonraki numunenin ağırlıkları 0,0001 gr hassasiyetindeki terazi ile ölçülüp deney öncesi ağırlıktan $\left(\mathrm{M}_{1}\right)$ deney sonrası ağırlık $\left(\mathrm{M}_{2}\right)$ çıkarılarak ağırlık kaybı $(\Delta \mathrm{m})$ hesaplandı. A ğırlık kaybı aşağıda verilen formül ile hesaplanmıştır.

$$
\Delta_{\mathrm{m}}=\mathrm{M}_{1}-\mathrm{M}_{2}
$$

Numunelerin ağırlık kaybı aşındırma işleme sonrasında ölçülerek aşınma oranları aşağıda verilen formül ile hesaplanmıştır.

$\mathrm{Ws}=\Delta \mathrm{m} / \rho \cdot \mathrm{F}_{\mathrm{N}} \cdot \mathrm{L}$ 
$\mathrm{Bu}$ formülde $\Delta \mathrm{m}$ : Ağırlık kaybı, $\rho$ : Yoğunluk, $\mathrm{F}_{\mathrm{N}}$ : Uygulanan yük ve L: Aşındırma mesafesini temsil etmektedir. Aşınma oranlarının belirlenmesinde 3 adet numune test edilmiş ve aritmetik ortalamalar verilmiştir.

Darbe numunelerinden elde edilen kırık yüzeyler Polaron marka kaplama cihazında altın/paladyum alaşımı ile kaplanmıştır. $10 \mathrm{~nm}$ kalınlığındaki bu kaplama elektriksel yüklemeyi önlemek için yapılmıştır. Daha sonra numuneler $15 \mathrm{kV}$ altında Jeol marka taramalı elektron mikroskobu ile incelenmiştir. Aşağıdaki şekilde bu çalışmada kullanılan test cihazları verilmiştir.
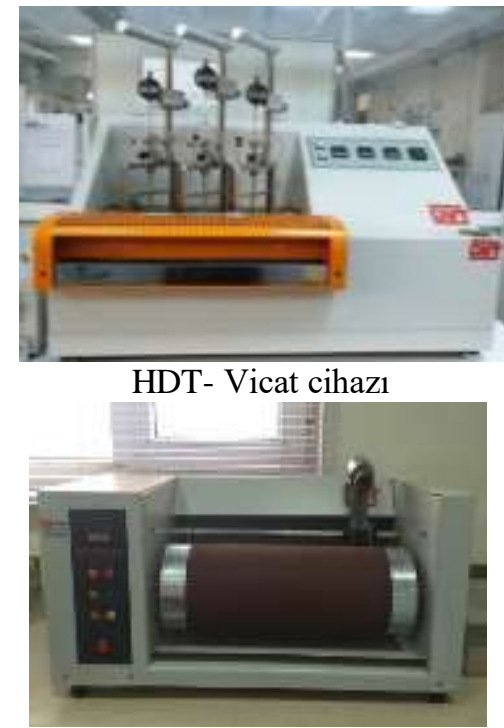

Aşınma cihazı

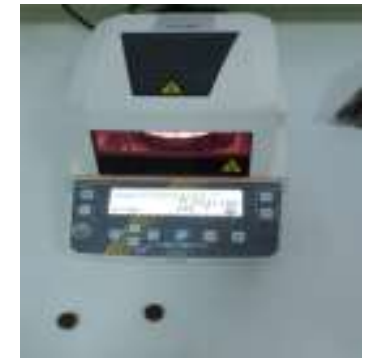

Nem ölçme

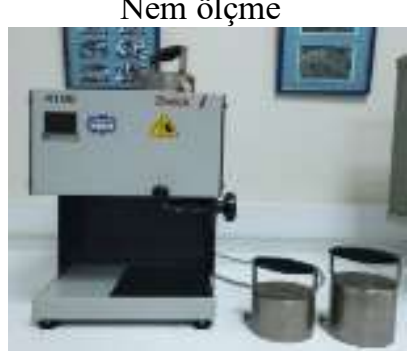

MFI cihazı

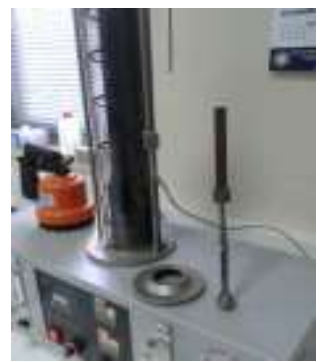

LOİ cihazı

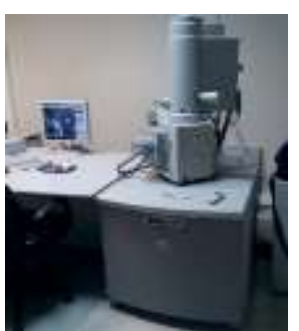

SEM

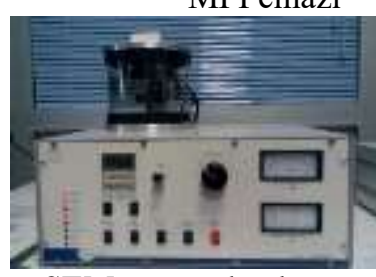

SEM umune kaplama

Şekil 3. $\mathrm{PP} / \mathrm{ZÇT/MA-g-PP}$ polimer kompozitinin özelliklerinin belirlenmesinde kullanılan test cihazları

\section{Bulgular ve Tartışma}

\subsection{Fiziksel ve aşınma özellikleri}

Polipropilen içerisine farklı oranlarda zeytin çekirdeği tozlarının katılmasıyla elde edilen polimer kompozitinin Vicat testi sonucu elde edilen yumuşama sıcaklığı değerleri şekil 4a'da verilmiştir. Grafikten de anlaşılacağ 1 gibi matris içerisine zeytin çekirdeği tozlarının ilavesiyle kompozitin Vicat yumuşama sıcaklığı değerinin artığı görülmektedir. Şekilden de görüldüğü gibi saf polipropilenin Vicat yumuşama sıcakllğ 1 değeri $139{ }^{\circ} \mathrm{C}$ olarak ölçülmüşken matrise ağırlıkça $\% 20$ oranında zeytin çekirdeği katıldığında bu değerin yaklaşık \%6 oranında artarak $147^{\circ} \mathrm{C}$ 'ye çıktığı tespit edilmiştir. Taşdemir [8]'in yapmış olduğu bir çalışmada da benzer sonuçlar görülmüştür. Taşdemir çalışmasında polipropilen içerisine \%40'a kadar ayrı ayrı badem kabuğu ve zeytin çekirdeği tozları katmış ve Vicat yumuşama sıcaklığının her iki dolgu türünde de yaklaşık 10 derece arttığını belirlemiştir.

Şekil 4b'ye baktığımızda ısıl çarpılma sıcaklık değerlerinde de benzer durumun olduğu görülmektedir. Burada polipropilen içerisinde zeytin çekirdeği oranının artmasıyla ısıl çarpılma sıcaklığının arttığı görülmektedir. Saf polipropilenin 1sıl çarpılma sıcaklığı $58{ }^{\circ} \mathrm{C}$ ölçülmüştür ve kompozit içerine zeytin çekirdeği tozunun ağırlıkça \%20 oranında katılmasıyla bu değerin $63,7^{\circ} \mathrm{C}$ 'ye çıktığı görülmektedir. Bu durumun zeytin çekirdeğinin sert yapısından ve matris ile zeytin çekirdeği arasındaki yapışmayı arttırsın diye katılan maleik anhidrit aşılı poliproilenin ilavesinden kaynaklandığı düşünülmektedir. 
Şekil 4c'de kompozit içerisinde zeytin çekirdeği oranının artmasıyla nem emme miktarının da arttığı görülmektedir. Şekilden den anlaşıldığı gibi saf polipropilenin nem emme oranının \%0,56 olduğu ve $\% 20$ zeytin çekirdeği katk1lı grupta ise bu değerin \%1,3 olduğu görülmektedir. Nem emme miktarındaki bu artış oranının yaklaşık \%132 olduğu tespit edilmiştir. Nem miktarındaki bu artışın sebebi, apolar karakterde olan polipropilen içerisine polar olan zeytin çekirdeğinin katılmasıdır. Zeytin çekirdeği tozlarının polar karakterde olması daha fazla su emmesini sağlamaktadır [2-6]. Banat ve arkadaşlarının [6] yapmış oldukları bir çalışmada yüksek yoğunluklu polietilen içerisinde zeytin çekirdeği tozlarının oranının artmasıyla su emme değerinin yükseldiğini tespit etmişlerdir.

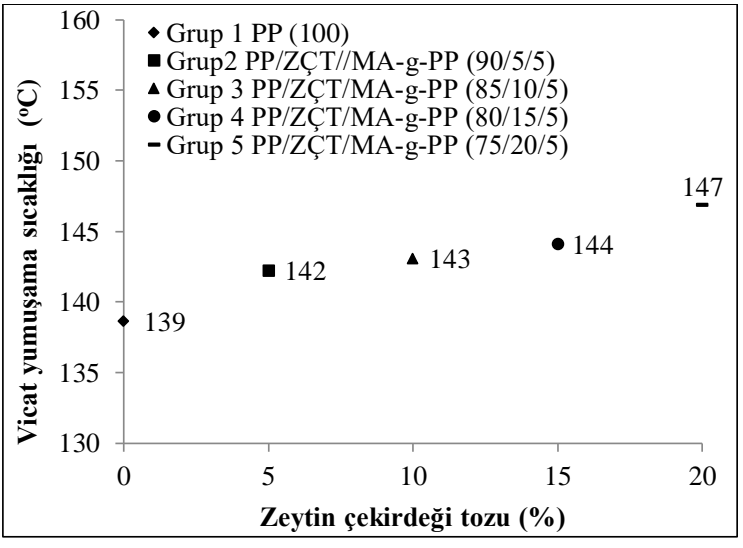

$\mathbf{a}$

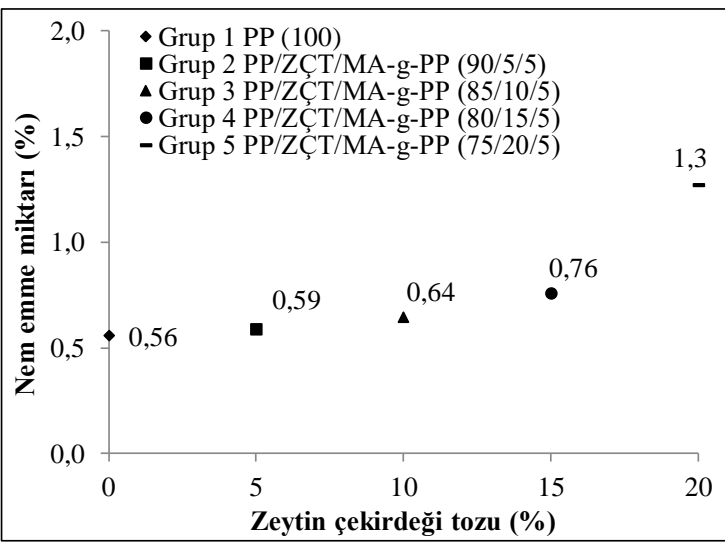

c

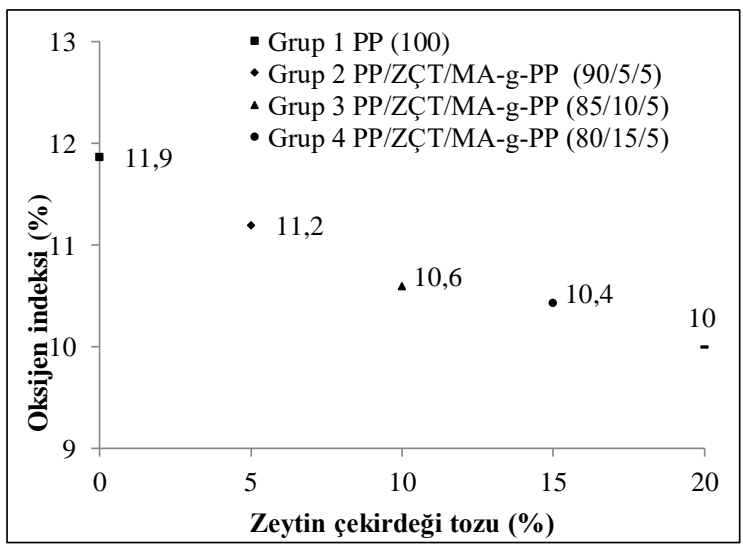

e

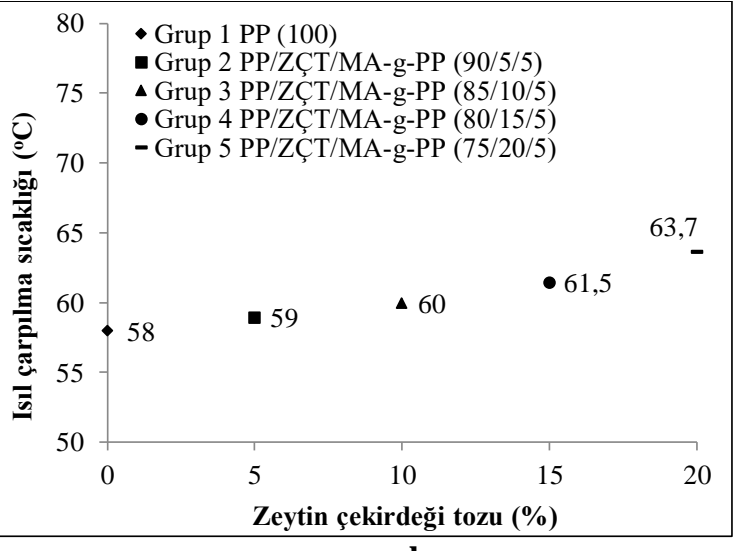

b
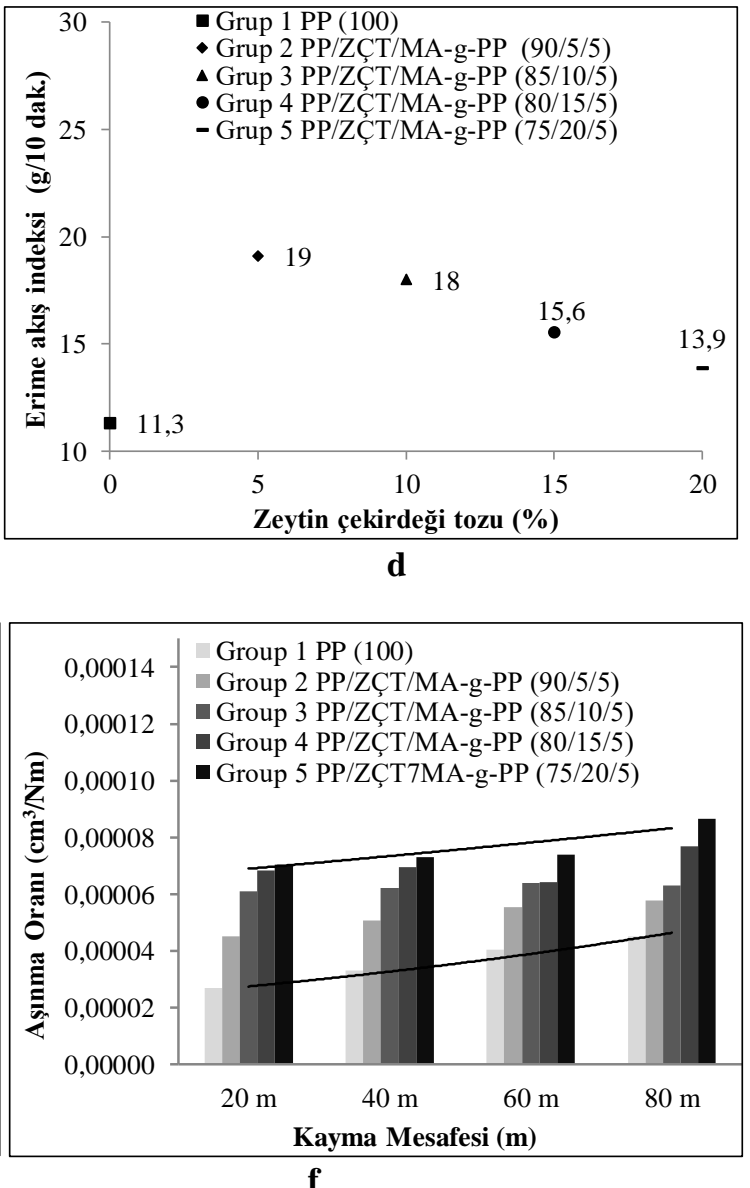

Şekil 4. PP/ZÇT/MA-g-PP polimer kompozitinin fiziksel özellikleri ve aşınma oranı 
Şekil 4d'de zeytin çekirdeği ilavesiyle polimer kompozitinin erime akış indeksinin artığı fakat zeytin çekirdeği oranının artmasıyla bu değerin gittikçe düştüğü görülmektedir. Dikkat edilirse saf polipropilenin erime akış indeksi değerinin $11,3 \mathrm{~g} / 10$ dak değerinde olduğu ve sisteme $\% 5$ oranında zeytin çekirdeği ilavesiyle bu değerin artarak $19 \mathrm{~g} /$ dak değerine çıktığ fakat matris içerinde zeytin çekirdeğinin oranının daha da arttırılması ile bu değerin 13,9 g/dak değerine kadar düştüğü grafikten görülmektedir. Yani matris içerisinde zeytin çekirdeği oranının artması ile polimer kompoziti daha zor bir akış göstermektedir. Burada şunu da belirtmek gerekir ki malzemenin zor akış göstermesi özellikle enjeksiyon makinesinde kalıbı tam doldurmama problemine yol açar.

Şekil 4e'ye baktığımızda zeytin çekirdeği oranının artmasıyla oksijen indeksi değerinin gittikçe düştüğü görülmektedir. Örneğin saf polipropilenin limit oksijen indeksi değerinin \%11,9 olduğunu fakat zeytin çekirdeği oranının artmasıyla limit oksijen indeksi değerinin \%10 seviyesine kadar düştüğü görülmektedir.

Şekil 4f’de gösterilen aşınma oranı ve kayma mesafesi grafiğine baktığımızda öncelikle her aşındırma mesafesinde (20-40-60-80 m) zeytin çekirdeğinin matris içerindeki oranlarının artmasıyla aşınma oranlarının artığını söylemek gerekir. Matris içerisinde zeytin çekirdeği oranının artmasıyla aşınma oranı değerlerinin de arttığı şekilden anlaşılmaktadır. Aşınma oranındaki artışın matris ile dolgu arasındaki bağlanmanın zayıf olmasından dolayısıyla zeytin çekirdeği partiküllerinin matristen kolayca ayrılmalarından kaynaklandığı düşünülmektedir. Taşdemir [8]'in yapmış olduğu bir çalışmada da benzer sonuçlar görülmüştür. Taşdemir çalışmasında polipropilen içerisine $\% 40$ 'a kadar ayrı ayrı badem kabuğu ve zeytin çekirdeği tozları katmış ve aşınma oranının her iki dolgu türünde de arttığını belirlemiştir. Aynı zamanda aşınma mesafesinin artmasıyla da aşınma oranının da artığını çalışmasında rapor etmiştir.

\subsection{Morfolojik özellikler}

Saf PP, PP/zeytin çekirdeği tozu/MA-g-PP (90/5/5), PP/zeytin çekirdeği tozu/MA-g-PP (85/10/5) ve PP/zeytin çekirdeği tozu/MA-g-PP (80/15/5) örneklerinin SEM görüntüleri Şekil 5'te verilmiştir. SEM fotoğraflarına bakıldığında matris ve zeytin çekirdeği tozları net olarak gözükmektedir. Polipropilen ve zeytin çekirdeği arasındaki ara yüzey gerilimi faz morfolojisi için çok önemlidir. Görüntüler incelendiğinde bazı bölgelerde zayıf bazı bölgelerde ise daha iyi ara yüzey yapışmasının olduğu görülmektedir. Tozların matrise yapışma yeteneği ve homojen olarak dağılması herhangi bir polimer kompozitinin özelliklerini anlamada çok yardımcı olmaktadır. Şekil 5'ten de anlaşıldığı gibi, bazı zeytin çekirdeği parçacıklarının matrise olan zayıf bağlanmalarından dolayı yerlerinden çıktıkları görülmektedir. Bazılarının ise polipropilen matris içerisinde gömülü oldukları görülmektedir. $\mathrm{Bu}$ çalışmada artan zeytin çekirdeği oranınca yeterli uyumluluk maddesi kullanılmaması sadece \%5 oranında kullanılması böyle bir sonuca sebebiyet vermektedir. Literatürdeki bazı çalışmalarda yüksek oranlarda dolgu kullanımı ara yüzeyde daha az yapışmanın olduğunu ortaya koymaktadır. Bazı araştırmacılar yapmış oldukları çalışmalarda matris ile dolgu malzemesi arasında yapışmanın artırılması veya kalıplama kolaylığı sağlamak için çeşitli maddeler kullanmışlardır. Örneğin, Kızıltaş ve arkadaşlarının [14] yapmış oldukları bir çalışmada poli (etilen tereftalat) (PET) ve poli (trimetilen tereftalat) (PTT) polimerlerine mikro kristal selüloz katıp bir polimer kompoziti elde etmişlerdir. Yağlayıc1 (lubricant) olarak kompozite struktol ticari isimli bir malzeme kompozitin daha kolay kalıplanması için işlem kolaylaştırıcı olarak katılmıştır. Zhang ve arkadaşları ise [15] yapmış oldukları bir çalışmada polipropilen/mikro kristalin selüloz polimer kompozitlerinde polipropilen ile selüloz arasındaki yapışmanın artırılması kompozite maleik anhidrit aşı1ı polipropilen (PP-g-MA) ve metil akrilik asit glisidil ester aşı1ı PP (PP-g-GMA) katmışlardır. Bizim yapmış olduğumuz bu çalışmada herhangi bir yağlayıcı kullanılmamıştır. Valves ve arkadaşları [16] polimer esaslı kompozitlerde dolgu malzemesi olarak kullanılan zeytin çekirdeği konusunda kapsamlı bir review yayınlamışlardır. Benzer bir çalışma ise Banat [17] tarafindan yapılmıştır. 


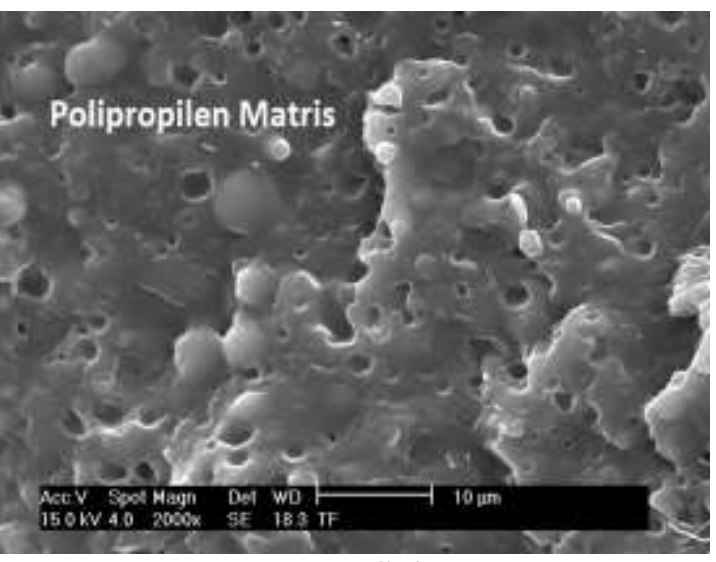

Saf PP

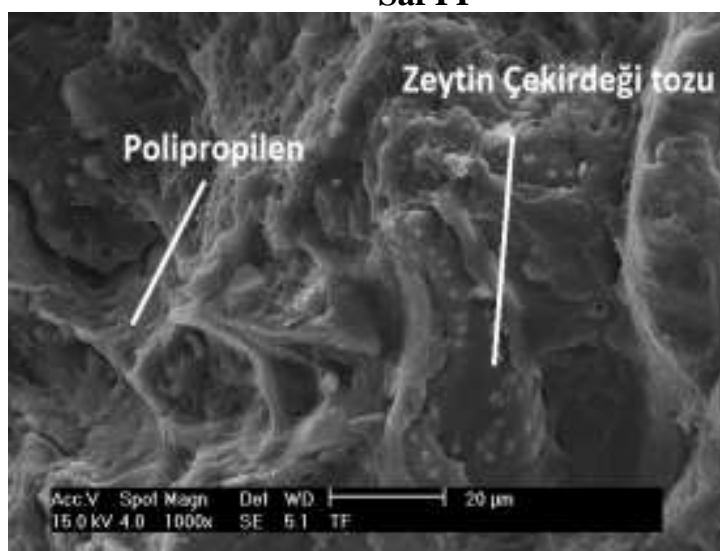

3. Grup $(85 / 10 / 5)$

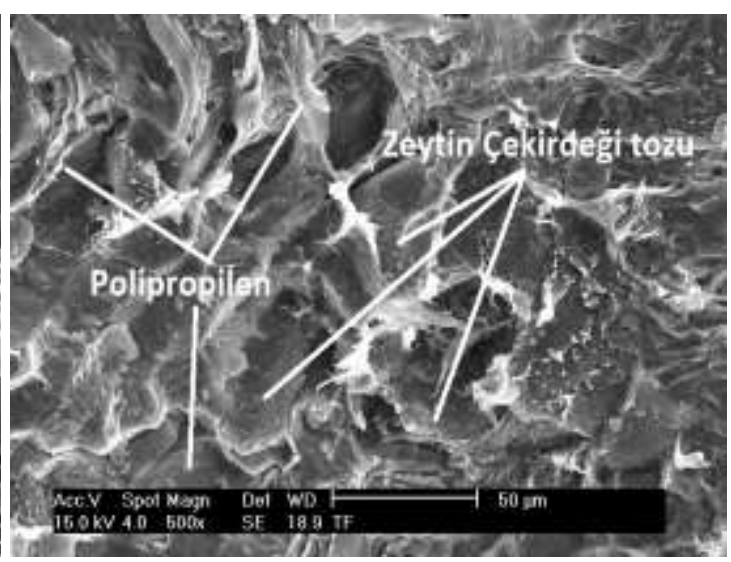

2. Grup $(90 / 5 / 5)$

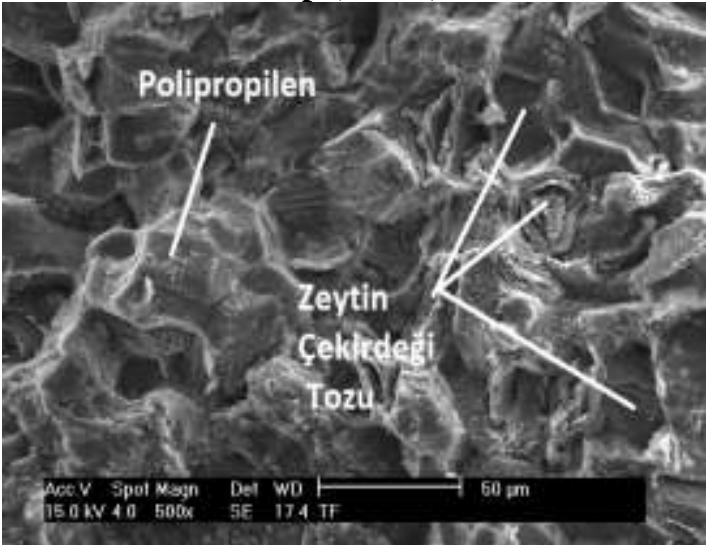

4. Grup $(80 / 15 / 5)$

Şekil 5. PP/ZÇT/MA-g-PP polimer kompozitinin SEM görüntüleri

\section{Sonuç ve Öneriler}

Atık zeytin çekirdeklerinden elde edilen tozların polipropilen matrisli kompozitlerde potansiyel bir dolgu malzemesi olarak kullanımı bu çalışmada ortaya konulmuştur. Elde edilen kompozitte zeytin çekirdeğinin miktarı arttıkça Vicat yumuşama sıcaklığı, 1sıl çarpılma sıcaklığı, nem emme miktarı, erime akış indeksi, limit oksijen indeksi, aşınma oranlarını ve morfolojinin nasıl etkilendiği belirlenmiştir. Veriler sonucunda polipropilen içerisindeki zeytin çekirdeği oranının artması ile Vicat yumuşama sıcaklığı, ısıl çarpılma sıcaklığı, nem emme miktarı ve aşınma oranı değerlerinin arttığı tespit edilmiştir. Buna karşılık erime akış ve limit oksijen indeksi değerlerinin ise düştüğü belirlenmiştir. Elde edilen polimer kompozitinin vicat yumuşama ve 1sıl çarpılma sıcaklıklarında bir artışı olması ve düşen değerlerde uyumluluk maddesinin oranının veya cinsinin değiştirilmesi gibi çeşitli yöntemler kullanılarak geliştirilebilir olması zeytin çekirdeklerinin polimerlerde dolgu maddesi olarak kullanımları konusunda ümit vaat eden bir durumu oluşturmaktadır.

\section{Yazarların Katkısı}

Çalışmaya yazarlar eşit oranda katkı sunmuştur.

\section{Çıkar Çatışması Beyanı}

Yazarlar arasında herhangi bir çıkar çatışması bulunmamaktadır.

\section{Araştırma ve Yayın Etiği Beyanı}

Yapılan çalışmada araştırma ve yayın etiğine uyulmuştur. 


\section{Kaynaklar}

[1] Naghmouchi I., Espinach F.X., Mutje P., Boufi S. 2015. Polypropylene composites based on lignocellulosic fillers: How the filler morphology affects the composite properties. Materials Design, 65: 454-461.

[2] Asim M., Abdan K., Jawaid M., Nasir M., Dashtizadeh Z., Ishak M.R., Hoque M.E. 2015. A review on pineapple leaves fibre and its composites. International Journal of Polymer Science, 2015 (6): 1-16.

[3] Azwa Z.N., Yousif B.F., Manalo A.C., Karunasena W. 2013. A review on the degradability of polymeric composites base on natural fibres. Materials Desing, 47: 424-442.

[4] Ashori A. 2008. Wood-plastic composites as promising green composites for automotive industries. Bioresour Technol., 99 (11):4661-4667.

[5] John M.J., Thomas S 2008. Biofibres and biocomposites carbohydr. Polymer, 71: 343-364.

[6] Banat R., Fares M.M. 2015. Olive oil waste filled high density polyethylene bio-composite: mechanical, morphological and water absorption properties. Int. Journal of Composite Materials, 5 (5): 133-141.

[7] Kılıçaslan C. 2016. Zeytin pirinas1/polyester kompozitin basma yükü altındaki mekanik özelliklerinin belirlenmesi. Mühendis ve Makina Dergisi, 57 (656): 26-30.

[8] Tasdemir M. 2017. Effects of olive pit and almond shell powder on polypropylene. Key Engineering Materials, 733: 65-68.

[9] Koutsomitopoulou A.F., Bénézet J.C., Bergeret A., Papanicolaou G.C. 2014. Preparation and characterization of olive pit powder as a filler to PLA-matrix bio-composites. Powder Technology, 255: 10-16.

[10] Djidjelli H., Benachour D., Boukerrou A., Zefouni O., Martinez-Véga J., Farenc J., Kaci M. 2007. Thermal, dielectric and mechanical study of poly(vinyl chloride)/olive pomace composites. Express Polymer Letters, 1: 846-852.

[11] Gümüş B.E., Yağcı Ö., Erdoğan D.C., Taşdemir M. 2019. Dynamical mechanical properties of polypropylene composites filled with olive pit particles. Journal of Testing and Evaluation, 47 (4): 2551-2561.

[12] Ayrılmış N., Büyüksarı U. 2010. Utilization of olive mill sludge in manufacture of lignocellulosic/polypropylene composite. Journal of Materials Science, 45 (5): 1336-1342.

[13] Öztürk N.K., Sever K., Seydibeyoğlu M.Ö., Sütçü M., Sarıkanat M., Seki Y. 2015. Pirina atığ1 katk11 termoplastik kompozitlerin termokinetik mikser ile üretimi. XIX. Ulusal mekanik kongresi, 24-28 Ağustos 2015 Karadeniz Teknik Üniversitesi, Trabzon, 787-793.

[14] Kızıltas A., Gardner D.J., Han Y., Yang H.S. 2010. Determining the mechanical properties of microcrystalline cellulose (MCC) filled PET/PTT blend composites. Wood Fiber Sci., 42 (2): 165-176.

[15] Zhang X., Shen J., Yang H., Lin Z., Tan S. 2011. Mechanical properties, morphology, thermal performance, crystallization behavior, and kinetics of $\mathrm{PP} /$ microcrystal cellulose composites compatibilized by two different compatibilizers. J. Thermoplast. Compos. Mater., 24 (6): 735753.

[16] Valvez S., Maceiras M., Santos P., Reis P.N.B. 2021. Olive Stones as filler for polymer-based composites:a review. Materials, 14: 845.

[17] Banat R. 2019. Olive pomace flour as potential organic filler in composite materials: A brief review. American Journal of Polymer Science, 9 (1): 10-15. 